\title{
NUMERICAL INVESTIGATION OF CHANNEL GEOMETRY ON THE PERFORMANCE OF A PEM FUEL CELL
}

\author{
I. KHAZAEE* \\ Department of Mechanical and Energy Engineering \\ Power and Water University of Technology \\ 16765-1719 Tehran, IRAN \\ E-mail: Imankhazaee@yahoo.com \\ M. MOHAMMADIUN \\ Department of Mechanical Engineering \\ Shahrood branch, Islamic Azad University \\ Shahrood, IRAN
}

\begin{abstract}
A complete three-dimensional and single phase model for proton exchange membrane (PEM) fuel cells was used to investigate the effect of using different channels geometry on the performances, current density and gas concentration. The proposed model was a full cell model, which includes all the parts of the PEM fuel cell, flow channels, gas diffusion electrodes, catalyst layers and the membrane. Coupled transport and electrochemical kinetics equations were solved in a single domain; therefore no interfacial boundary condition was required at the internal boundaries between cell components. This computational fluid dynamics code was employed as the direct problem solver, which was used to simulate the three-dimensional mass, momentum, energy and species transport phenomena as well as the electron- and proton-transfer process taking place in a PEMFC. The results showed that the predicted polarization curves by using this model were in good agreement with the experimental results and a high performance was observed by using circle geometry for the channels of anode and cathode sides. Also, the results showed that the performance of the fuel cell improved when a rectangular channel was used.
\end{abstract}

Key words: PEM fuel cell, rectangular, triangular, elliptical, numerical modeling, performance.

\section{Introduction}

A fuel cell is an electro-chemical energy device that converts the chemical energy of fuel directly into electricity and heat, with water as a by-product of the reaction. Based on the types of electrolytes used, they are categorized into polymer electrolyte membrane fuel cells (PEMFCs), solid oxide fuel cells (SOFCs), phosphoric acid fuel cells (PAFCs), molten carbonate fuel cells (MCFCs), and direct methanol fuel cells (DMFCs). The polymer exchange membrane fuel cell (PEMFC) is considered to be the most promising candidate for electric vehicles by virtue of its high power density, zero pollution, low operating temperature, quick start-up capability and long lifetime. A PEMFC can also be used in distributed power systems, submarines, and aerospace applications that described by Larminie and Dicks (2003).

Flow channel geometry is of critical importance for the performance of fuel cells containing proton exchange membranes (PEM) but is of less concern for solid oxide fuel cells (SOFC). The reactants, as well as the products, are transported to and from the cell through flow channels. Flow field

\footnotetext{
* To whom correspondence should be addressed
} 
configurations, including parallel, serpentine, interdigitated, and other combined versions, have been developed.

West and Fuller (1996) proposed a two-dimensional numerical analysis of the rib spacing in PEM electrode assemblies on current and water distribution within the cell. The results indicated that increasing the rib width strongly affected the membrane water content before the catalyst utilization is reduced. Therefore, the two-dimensional effect has a significant influence on water management.

Chiang and Chu (2006) investigated the effects of transport components on the transport phenomena and performance of PEM fuel cells by using a three-dimensional model. The impacts of the channel aspect ratio (AR) and GDL thickness were examined. It was found that a flat channel with a small AR or a thin GDL generates more current at low cell voltage due to the merits of better reactant gas transport and liquid water delivery.

Wang et al. (2001) developed a two-dimensional numerical model to study the two-phase flow transport in the air cathode of a PEMFC. In this paper, the model encompassed both single- and two-phase regimes corresponding to low and high current densities and was capable of predicting the transition between the two regimes.

Jenn-Kun Kuo et al. (2008) performed numerical simulations to evaluate the convective heat transfer performance and velocity flow characteristics of the gas flow channel design to enhance the performance of proton exchange membrane fuel cells (PEMFCs). Their study simulated low Reynolds number laminar flow in the gas flow channel of a PEMFC. The heat transfer performance and enhanced gas flow velocity characteristics of four different channel geometries were considered, namely a conventional straight gas flow channel and a gas flow channel with the three novel periodic patterns geometries.

The results indicated that, compared to the conventional gas flow channel, the novel gas flow channels proposed in this study provide a significantly improved convective heat transfer performance and a higher gas flow velocity and, hence, an improved catalysis reaction performance in the catalyst layer.

This study numerically investigated the effect of using different channels geometry on cell performance, temperature and species distribution of a PEM fuel cell. The objective of the current work is to show the effect of changing channel geometry that may be of interest to engineers attempting to develop the optimization of a PEMFC and to researchers interested in the flow modification aspects of the PEMFC performance enhancement.

\section{Numerical model}

The cathode electrochemical reactions produce a large amount of liquid water at low operating voltages. If the liquid water is not properly removed and accumulates in the pores of the porous layers, it restricts the oxygen transport to the gas diffusion layer and the catalyst layer, thereby reducing the electrochemical reaction rate.

The numerical model for the fuel cell used here includes the anode flow channels, anode gas diffusion layer, anode catalyst layer, proton exchange membrane, cathode catalyst layer, cathode gas diffusion layer, and cathode flow channels. Miniature fuel cells with dimensions of $5.28 \mathrm{~mm} \times 3.6 \mathrm{~mm} \times 40 \mathrm{~mm}$ are considered in this investigation. The gas diffusion layer is $0.21 \mathrm{~mm}$ thick, the catalyst layer is $0.012 \mathrm{~mm}$ thick, and the proton exchange membrane is $0.036 \mathrm{~mm}$ thick.

The geometrical relations in this study are for three different channels.

The physical problem considered in this paper is the three dimensional cell model of the PEMFC system as shown in Fig.1. 


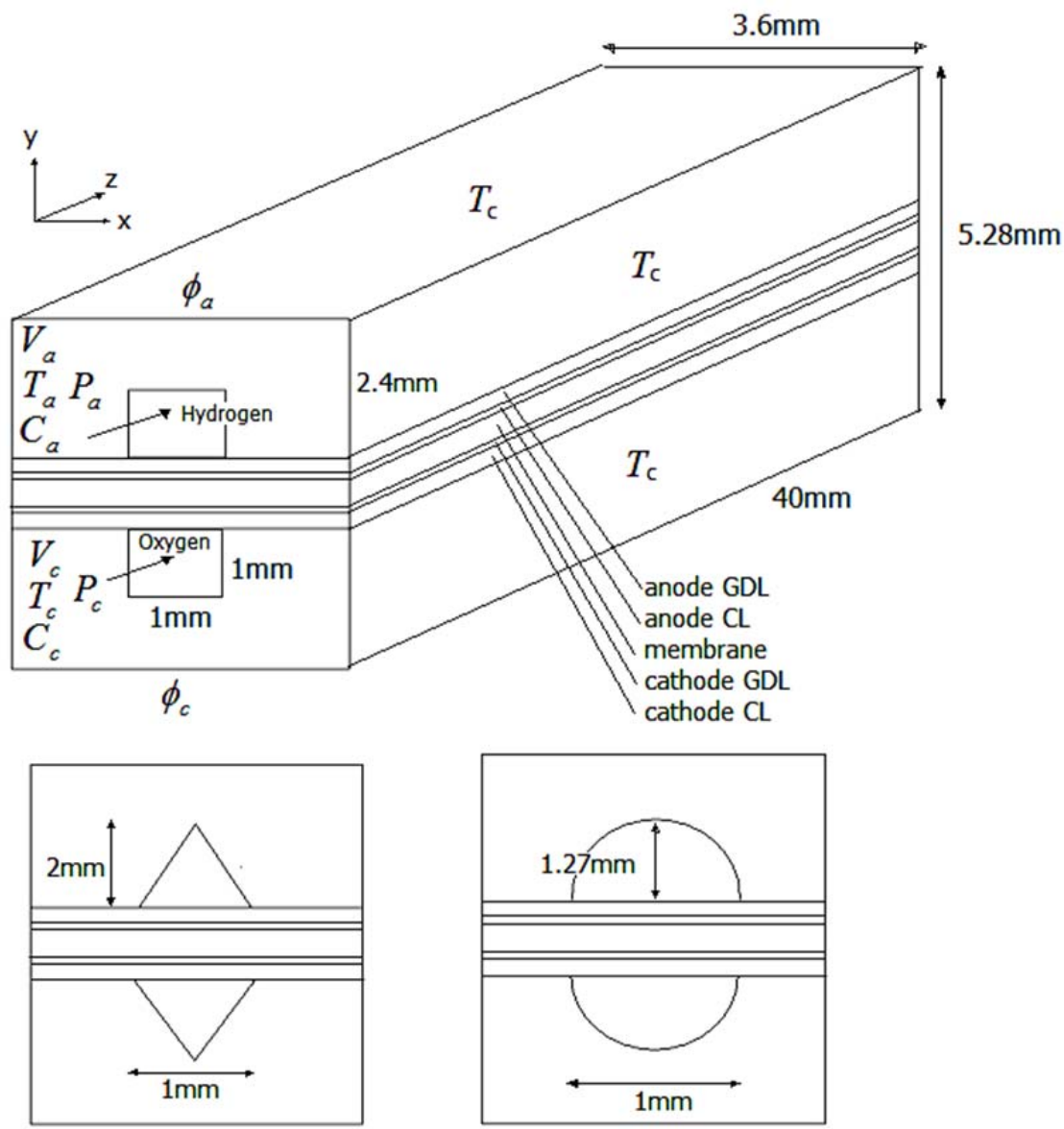

Fig.1. Schematic of physical model.

The proposed model does not require any internal boundary conditions between the components of PEM Fuel Cell system. The different physical properties and transport parameters are incorporated into a single set of governing equations using a single domain formulation. The model aims to study the electrochemical kinetics, current distribution, reactant flow fields and multi-component transport of oxidizer and fuel streams in a multi-dimensional domain. The assumptions made in developing the model are as follows:

\section{Ideal gas mixtures}

. Incompressible and laminar flow because of low flow velocities and low fuel consumption

. Isotropic and homogeneous porous electrodes, catalyst layers and membrane

. Negligible ohmic resistance at porous electrodes and current collectors

The model assumes that the system is steady; the inlet reactants are ideal gases; the flow is laminar; and the porous layers such as the diffusion layer, catalyst layer and PEM are isotropic. The model includes continuity, momentum and species equations for gaseous species, liquid water transport equations in the channels, gas diffusion layers, and catalyst layers, water transport equation in the membrane, electron and proton transport equations. The Bulter-Volumer equation was used to describe electrochemical reactions in the catalyst layers.

The conservation equations of mass, momentum, energy, species and charge are as follows

$$
\frac{\partial(\rho \varepsilon)}{\partial t}+\nabla \cdot(\varepsilon \rho \boldsymbol{u})=0
$$




$$
\begin{aligned}
& \frac{\partial(\rho \varepsilon \boldsymbol{u})}{\partial t}+\nabla \cdot(\varepsilon \rho \boldsymbol{u} \boldsymbol{u})=-\varepsilon \nabla p+\nabla \cdot(\varepsilon \mu \nabla \boldsymbol{u})+S_{u} \\
& \frac{\partial(\rho \boldsymbol{u}(E+p))}{\partial t}+\nabla \cdot((E+p) \rho \boldsymbol{u} \boldsymbol{u})=\nabla \cdot\left(\lambda_{\text {eff }} \nabla T-\sum_{k} h_{k} J_{k}+\left(\tau_{e f f} \cdot \boldsymbol{u}\right)\right)+S_{h}, \\
& \frac{\partial\left(\varepsilon X_{k}\right)}{\partial t}+\nabla \cdot\left(\varepsilon \boldsymbol{u} X_{k}\right)=\nabla \cdot\left(D_{k}^{e f f} \nabla X_{k}\right)+S_{k} \\
& \nabla \cdot\left(\sigma_{g}^{e f f} \nabla \varphi_{e}\right)+S_{\varphi}=0
\end{aligned}
$$

where $\boldsymbol{u}, X_{k}, h_{k}, \tau_{\text {eff }} \lambda_{\text {eff }}$ and $\varphi_{e}$ denote the intrinsic velocity vector, molar fraction of $k^{\text {th }}$ species, enthalpy of species $\mathrm{k}$, effective stress tensor which can be ignored due to the low velocity of laminar gas flow, effective thermal conductivity in a porous material consisting of the electrode solid matrix and gas and electrolyte phase potential, respectively. The corresponding source terms treating the electrochemical reactions and porous media are presented in Tab.1.

Table 1. Source terms.

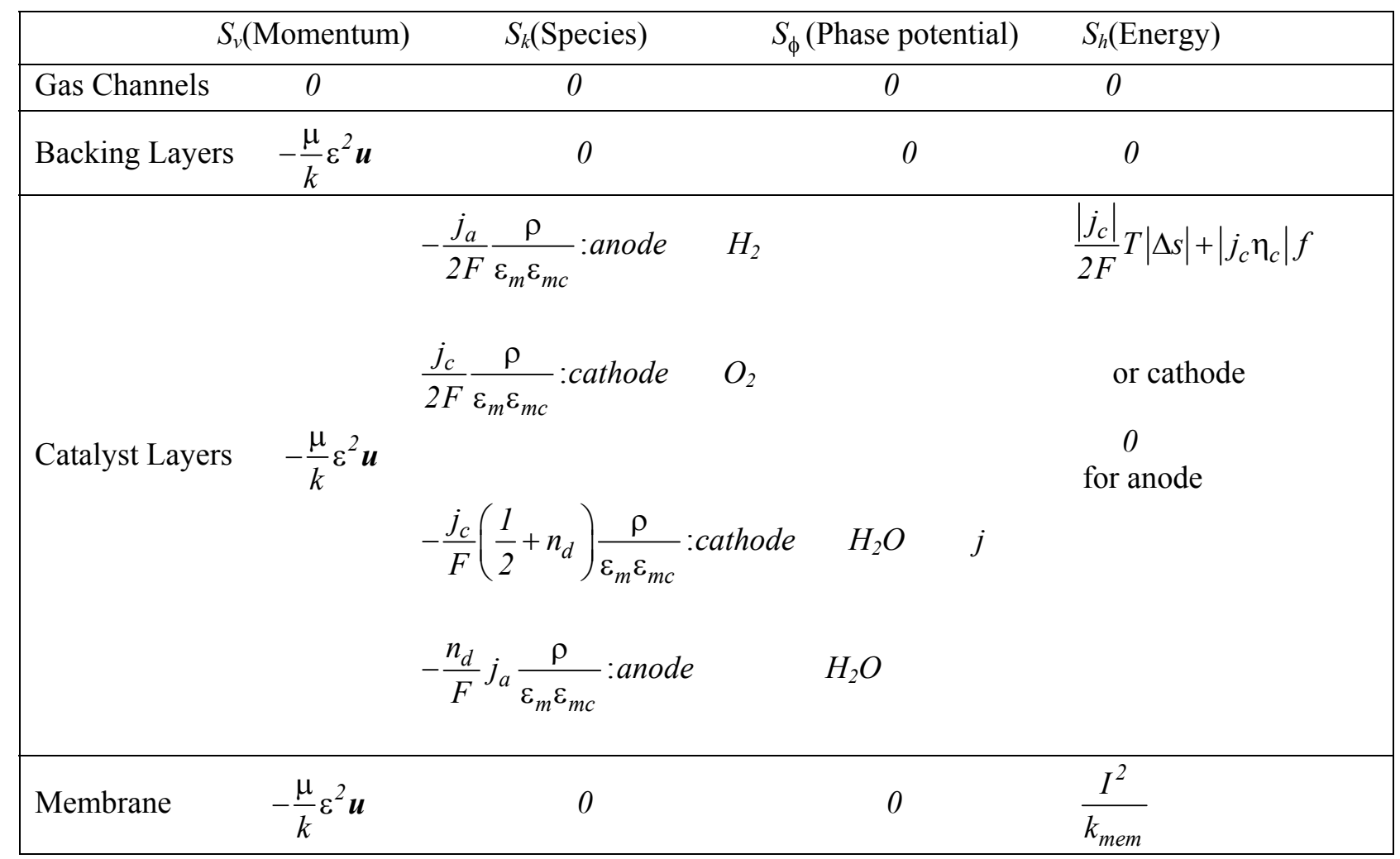




$$
\lambda_{e f f}=\varepsilon \lambda_{f}+(1-\varepsilon) \lambda_{s}
$$

where $\lambda_{s}$ is the thermal conductivity of the electrode solid matrix and $\lambda_{f}$ is the thermal conductivity of the gas, which can be expressed as a function of temperature

$$
\lambda_{f}=a_{0}+a_{1} T+a_{2} T^{2}+a_{3} T^{3} .
$$

It is of benefit to further explain the corresponding diffusivities of the governing equations. The diffusivities for species concentration equations and ionic conductivity for membrane phase potential equation are modified using Bruggman correlation to account for porous electrodes, which can be expressed as

$$
\begin{aligned}
& D_{k}^{e f f}=\varepsilon_{m}^{1.5} D_{k}, \\
& \sigma_{e}^{e f f}=\varepsilon_{m}^{1.5} \sigma_{e} .
\end{aligned}
$$

It is worth further explaining the mole fraction of oxygen appearing in Eq.(2.3) because oxygen is a gaseous species in the cathode flow channel and gas-diffusion electrode but becomes a species dissolved in the electrolyte in the catalyst layer and membrane regions. Our definition is given by

$$
X_{k}= \begin{cases}C_{k}^{g} / C_{\text {tot }} & \text { in gas } \\ C_{k}^{e} / C_{\text {tot }} & \text { in electrode }\end{cases}
$$

where $C_{k}$ is the molar concentration of species $k$ and superscripts $g$ and $e$ denote the gas and the electrolyte phases, respectively. Thus, $X_{k}$ is a true mole fraction in the gas phase but is a pseudo mole fraction when species $k$ is in the dissolved form. In addition, there is a discontinuity in the value of $X_{k}$ at the interface between the gas-diffusion electrode and the catalyst layer due to the following thermodynamic relation

$$
C_{k}^{e, s a t}=\frac{R T}{H} C_{k}^{g}
$$

where $H$ is Henry's law constant equal to $2 \times 10^{5}$ atm $\mathrm{cm} 3 / \mathrm{mol}$ for oxygen in the membrane.

Either generation or consumption of chemical species $k$ and the creation of electric current occurs only in the active catalyst layers where electrochemical reactions take place. The $S_{k}$ and $S_{F}$ terms are therefore related to the transfer current between the solid matrix and the membrane phase inside each of the catalyst layers. These transfer currents at anode and cathode can be expressed as follows

$$
j_{a}=a j_{0, a}^{r e f}\left(\frac{X_{H_{2}}}{X_{H_{2}, r e f}}\right)^{1 / 2}\left(\frac{\alpha_{a}+\alpha_{c}}{R T} \cdot F \cdot \eta\right),
$$




$$
j_{c}=-a j_{0, c}^{r e f}\left(\frac{X_{O_{2}}}{X_{\mid O_{2}, r e f}}\right)^{1 / 2}\left(-\frac{\alpha_{c} \cdot F}{R T} \cdot \eta\right)
$$

the above kinetics expressions are derived from the general Butler-Volmer equation based on the facts that the anode exhibits fast electrokinetics and hence a low surface overpotential to justify a linear kinetic rate equation, and that the cathode has relatively slow kinetics to be adequately described by the Tafel equation. In Eqs (2.12) and (2.13), the surface overpotential, $\eta(x, y)$, is defined as

$$
\eta(x, y)=\varphi_{s}-\varphi_{e}-V_{o c}
$$

where $\varphi_{s}$ and $\varphi_{e}$ stand for the potentials of the electronically conductive solid matrix and electrolyte, respectively, at the electrode electrolyte interface. $V o c$ is the reference open-circuit potential of an electrode. $V_{o c}$ is the reference open-circuit potential of an electrode. It is equal to zero on the anode but is a function of temperature on the cathode namely

$$
V_{o c}=0.0025 T+0.2329
$$

where $T$ is in Kelvin and $V_{o c}$ is in volts. Notice that $V o c$ is not the true open-circuit potential of an electrode, which would then depend upon reactant concentrations according to the Nernst equation.

Equation (2.9), which is a rewritten form of the Nernst equation, precisely describes the effect of decreasing transfer current under hydrogen dilution. The dependence of the cathodic exchange current density on temperature can be fitted as

$$
\frac{i_{0}(T)}{i_{0}(353 K)}=\exp (0.014189(T-353)) \text {. }
$$

The species diffusivity $D_{k}$ varies in different subregions of the PEMFC depending on the specific physical phase of component $k$. In flow channels and porous electrodes, species $k$ exists in the gaseous phase, and thus the diffusion coefficient takes the value in gas, whereas species $k$ is dissolved in the membrane phase within the catalyst layers and the membrane, and thus takes the value corresponding to dissolved species, which is usually a few orders of magnitude lower than that in gas. In addition, the diffusion coefficient is a function of temperature and pressure.

$$
D(T)=D_{0}\left(\frac{T}{T_{0}}\right)^{3 / 2}\left(\frac{p_{0}}{p}\right)
$$

The proton conductivity in the membrane phase has been correlated as

$$
\sigma_{e}(T)=100 \exp \left[1268\left(\frac{1}{303}-\frac{1}{T}\right)\right](0.005139 \xi-0.00326)
$$

where the water content in the membrane, $\xi$, depends on the water activity, $a$, according to the following fit of the experimental data 


$$
\xi= \begin{cases}0.043+17.18 a-39.85 a^{2}+36 a^{3} & 0 \prec a \leq 1 \\ 14+1.4(a-1) & 1 \leq a \leq 3\end{cases}
$$

The water activity is in turn calculated by

$$
a=\frac{X_{\mathrm{H}_{2} \mathrm{O}} \mathrm{p}}{p_{\text {sat }}}
$$

where the saturation pressure of water vapor can be computed from the following empirical equation

$$
\ln \left(p^{\text {sat }}\right)=70.43464-\frac{7362.698}{T}+0.006952 T-9 \ln (T) .
$$

In a fuel cell system, the inlet flow rates are generally expressed as stoichiometric ratios of inlet streams based on a reference current density. The stoichiometric ratios inlet streams are given by the following equations.

$$
\begin{aligned}
S^{\text {anode }} & =C_{\mathrm{H}_{2}} v^{\text {anode }} \frac{2 F}{I_{\text {ref }} A}, \\
S^{\text {cathode }} & =C_{\mathrm{O}_{2}} v^{\text {cathode }} \frac{4 F}{I_{\text {ref }} A} .
\end{aligned}
$$

Water transport through the polymer electrolyte membrane has been investigated by several researchers in different aspects. Most interesting studies in this area include the determination of water diffusion coefficient by Zawodzinski et al. (1995) and water drag coefficient by Zawodzinski et al. (1991) and investigating the diffusion of water in Nafion membranes by Motupally et al. (2000).

The electro-osmotic drag coefficient is defined as the number of water molecules transported by each hydrogen proton $H^{+}$. The electro-osmotic drag coefficient can be expressed with the following equation

$$
n_{d}=\frac{2.5 \xi}{22}
$$

The diffusion coefficient of water in the polymer membrane is also highly dependent on the water content of the membrane. The relation is given as

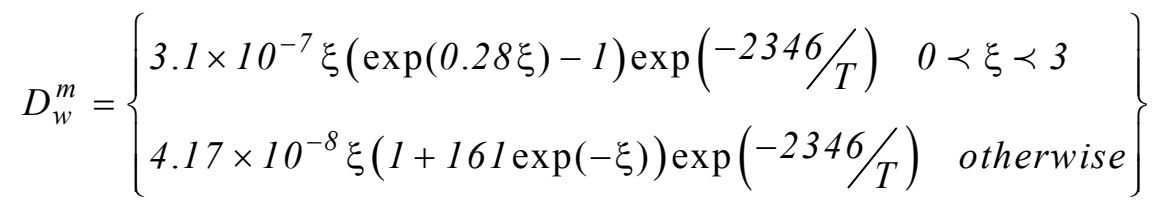

Once the electrolyte phase potential is determined in the membrane, the local current density along the axial direction can be calculated as follows 


$$
I(y)=-\left.\sigma_{e}^{e f f} \frac{\partial \varphi_{e}}{\partial x}\right|_{x=I . F}
$$

where I.F. means the interface between the membrane and cathode catalyst layer. The average current density is then determined by

$$
I_{\text {avg }}=\frac{1}{L} \int_{0}^{L} I(y) d y
$$

where $L$ is the cell length.

There are natural boundary conditions of zero-flux prescribed everywhere else than the inlet and outlets of the flow channels. The boundary conditions prescribed at the inlets of the gas channels are

\begin{tabular}{|l|l|}
\hline$u_{\text {in }}^{\text {anode }}=u_{a}^{0}$ & $u_{\text {in }}^{\text {cathode }}=u_{c}^{0}$ \\
\hline$C_{H_{2}}^{\text {anode, in }}=C_{\mathrm{H}_{2}}^{0}$ & $C_{\mathrm{O}_{2}}^{\text {cathode, in }}=C_{\mathrm{O}_{2}}^{0}$ \\
\hline$C_{\mathrm{H}_{2} \mathrm{O}}^{\text {anode,in }}=C_{\mathrm{H}_{2} \mathrm{O}}^{0, a}$ & $C_{\mathrm{H}_{2} \mathrm{O}}^{\text {cathode, in }}=C_{\mathrm{H}_{2} \mathrm{O}}^{0, c}$ \\
\hline
\end{tabular}

A mesh of $88 \times 700$ was found to provide required spatial resolution for different channel geometry. The solution is considered to be converged when the difference between successive iterations is less than $10^{-7}$ for all variables.

The electrochemical and transport parameters used in these simulations are summarized in Tab.2, and the operational parameters are presented in Tab.3.

Table 2. Electrochemical and transport properties.

\begin{tabular}{|lcc|}
\hline \multicolumn{1}{|c}{ Description } & Unit & Value \\
\hline Anode reference exchange current density & $\mathrm{A} / \mathrm{m}^{3}$ & $1.5 e 9$ \\
Cathode reference exchange current density & $\mathrm{A} / \mathrm{m}^{3}$ & 4000000 \\
Anode transfer coefficient & & 2 \\
Cathode transfer coefficient & $\mathrm{C} / \mathrm{mol}$ & 2 \\
Faraday constant & $\mathrm{m}^{2} / \mathrm{s}$ & 96487 \\
$\mathrm{H}_{2}$ Diffusivity & $\mathrm{m}^{2} / \mathrm{s}$ & $3 e-5$ \\
$\mathrm{O}_{2}$ Diffusivity & $\mathrm{m}^{2} / \mathrm{s}$ & $3 e-5$ \\
$\mathrm{H}_{2} \mathrm{O}$ Diffusivity at anode & $\mathrm{m}^{2} / \mathrm{s}$ & $3 e-5$ \\
$\mathrm{H}_{2} \mathrm{O}$ Diffusivity at cathode & & $3 e-5$ \\
Anode backing layer porosity & & 0.5 \\
Cathode backing layer porosity & $\mathrm{m}^{2}$ & 0.5 \\
Permeability of anode backing layer & $\mathrm{m}^{2}$ & $e-12$ \\
Permeability of cathode backing layer & $\mathrm{kg}^{2} / \mathrm{mol}$ & $e-12$ \\
Eigenvaluent Weight of membrane & & 1.1 \\
\hline
\end{tabular}


Table 3. Operational parameters.

\begin{tabular}{|lcc|}
\hline \multicolumn{1}{|c}{ Description } & Unit & Value \\
\hline Reference average current density & $\mathrm{A} / \mathrm{cm}^{2}$ & 1.0 \\
Anode inlet velocity & $\mathrm{m} / \mathrm{s}$ & 1.5 \\
cathode inlet velocity & $\mathrm{m} / \mathrm{s}$ & 2 \\
Anode inlet pressure & $\mathrm{Atm}$ & 2 \\
Cathode inlet pressure & $\mathrm{Atm}$ & 2 \\
Cell temperature & $\mathrm{C}^{*}$ & 70 \\
Anode inlet molar concentration & & 35.667 \\
Hydrogen & $\mathrm{mol} / \mathrm{m}^{3}$ & 0 \\
Oxygen & $\mathrm{mol} / \mathrm{m}^{3}$ & 16.121 \\
Water vapor & $\mathrm{mol} / \mathrm{m}^{3}$ & \\
Cathode inlet molar concentration & & 0 \\
Hydrogen & $\mathrm{mol} / \mathrm{m}^{3}$ & 7.51 \\
Oxygen & $\mathrm{mol} / \mathrm{m}^{3}$ & 16.121 \\
Water vapor & $\mathrm{mol} / \mathrm{m}^{3}$ & \\
\hline
\end{tabular}

\section{Results and discussion}

In order to show that the program in this study can handle the cell performance of a PEMFC, we apply the present method to solve the whole of a PEMFC as described by Miansari et al. (2009). The physical parameters and properties of the fuel cell are listed in Fig.2. The mesh employed for the comparison with the reference was $241 \times 74 x 25$. The steady-state solution is obtained by a numerical procedure as mentioned in the previous section. As shown in Fig.2, the result of the present predictions of the polarization curve agreeing fairly closely with Miansari et al. (2009) gives one confidence in the use of the present program.

Figure 3 illustrates the polarization curves of the fuel cell for three channel geometries of rectangular, triangular and elliptical shape to investigate the influence of the internal flow modification on the overall fuel cell performance. An overall inspection of Fig.3 indicates that at the conditions of the higher operating voltage (lower over potential), the influence of the internal flow modification on the overall fuel cell performance is negligibly small. At lower operating voltage conditions, on the other hand, the effect of the internal flow modification on the polarization curves becomes important. Also, Fig. 3 shows that the overall fuel cell performance is at a higher value when the geometry of the channel is rectangular but when the geometry of the channels shift to triangular and elliptical the cell performance decreases. This is due to the fact that a reflection of the more efficient fuel transport and the chemical reaction reduces the local current density more obviously in the downstream region. 


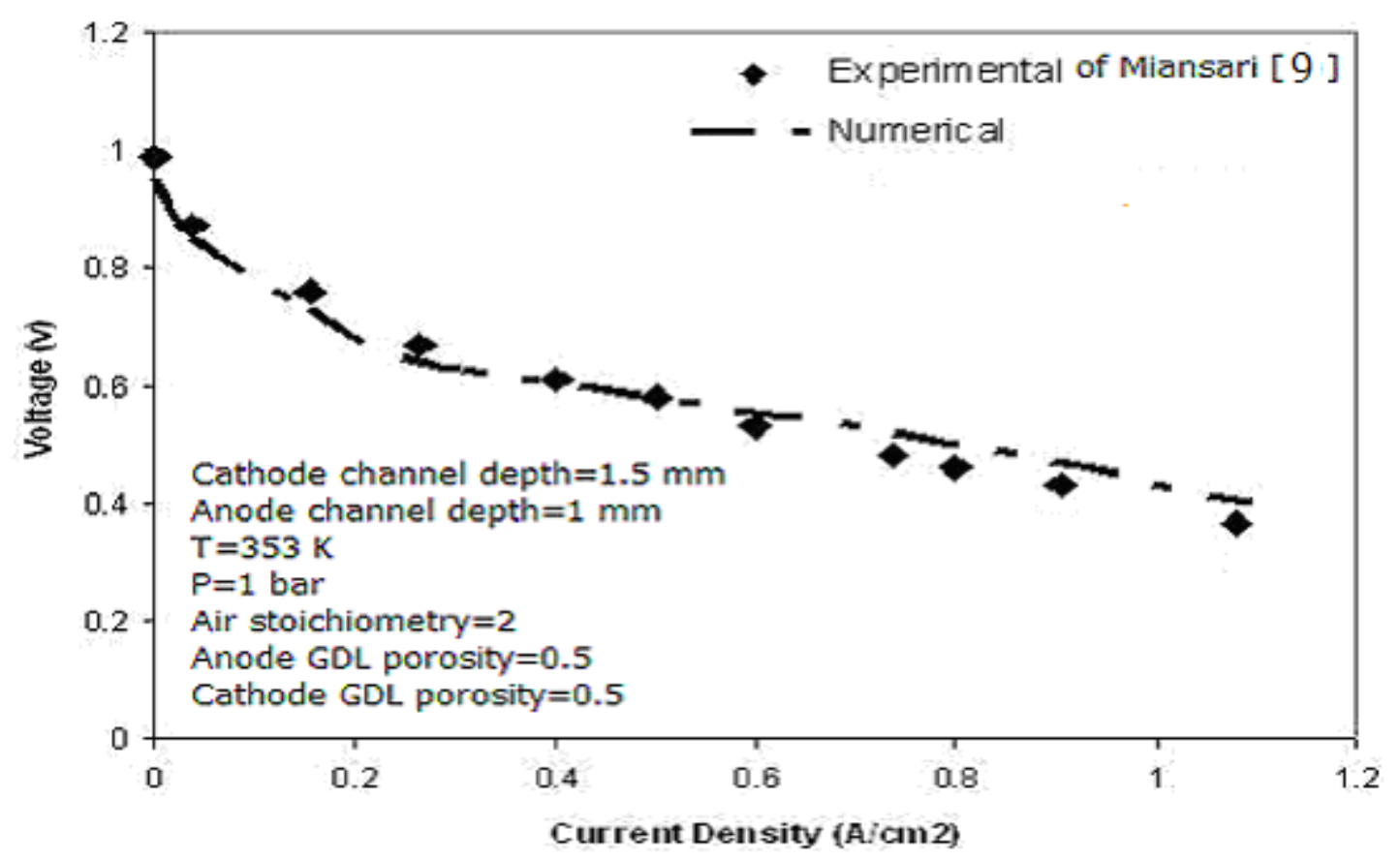

Fig.2. Comparison of results of this paper and results of Miansari et al (2009).

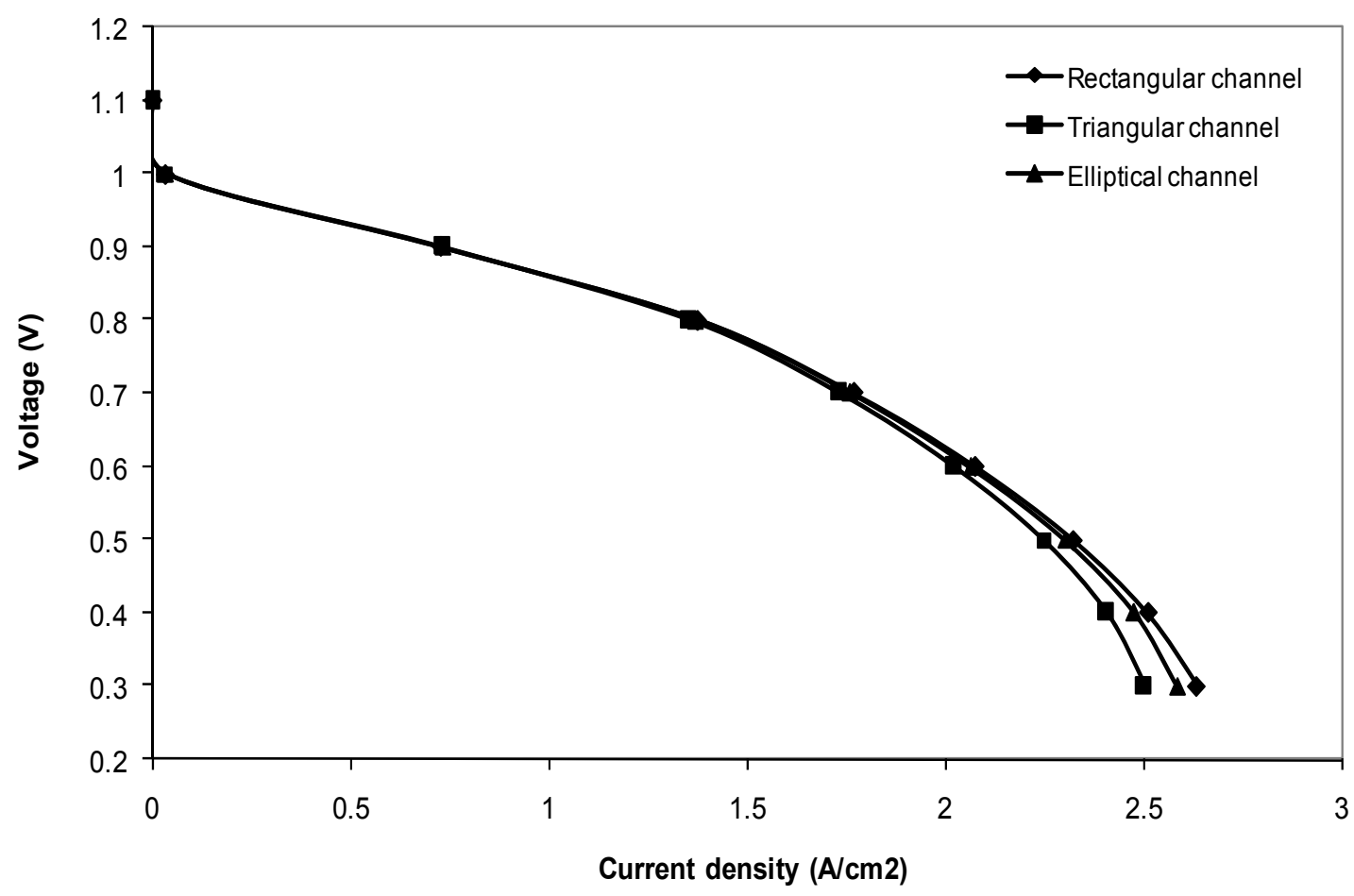

Fig.3. Variation of cell performance at different channel geometries. 
In Fig.4, the local current density along the catalyst surface at cell voltage of $0.3 \mathrm{~V}$ increases when the axial direction $z$ increases. It is clear that the local current density is at a higher value for the triangular and elliptical channel at the inlet to the channel but for the rectangular channel at the outlet of the channel. It is due to more intensive blockage of the fuel gas at the inlet of the channel and forcing more fuel gas into the gas diffusion layer to enhance the chemical reaction at the catalyst layer for triangular and elliptical channels.

Figure 5 depicts the transverse distributions of water mole fraction at $0.3 \mathrm{~V}$ cell voltage for different channel geometries of rectangular, triangular and elliptical shape along the membrane. It is clear that the liquid water mole fraction gradually increases with increasing $z$ because the produced liquid water moves to the downstream due to the gas phase shear forces. It is found from Fig.5 that the water mole fraction for a triangular channel is at a higher value than for the elliptical and rectangular channels and the reduction of the water mole fraction in the rectangular channel is a reflection of the more efficient fuel transport and the chemical reaction but less flow into the GDL along the channel.

Figure 6 shows the influence of the internal flow modification on the axial distribution of temperature at $0.3 \mathrm{~V}$ cell voltage for different channel geometries of rectangular, triangular and elliptical shape along the catalyst surface. It is clear that the temperature gradually increases with increasing $z$.

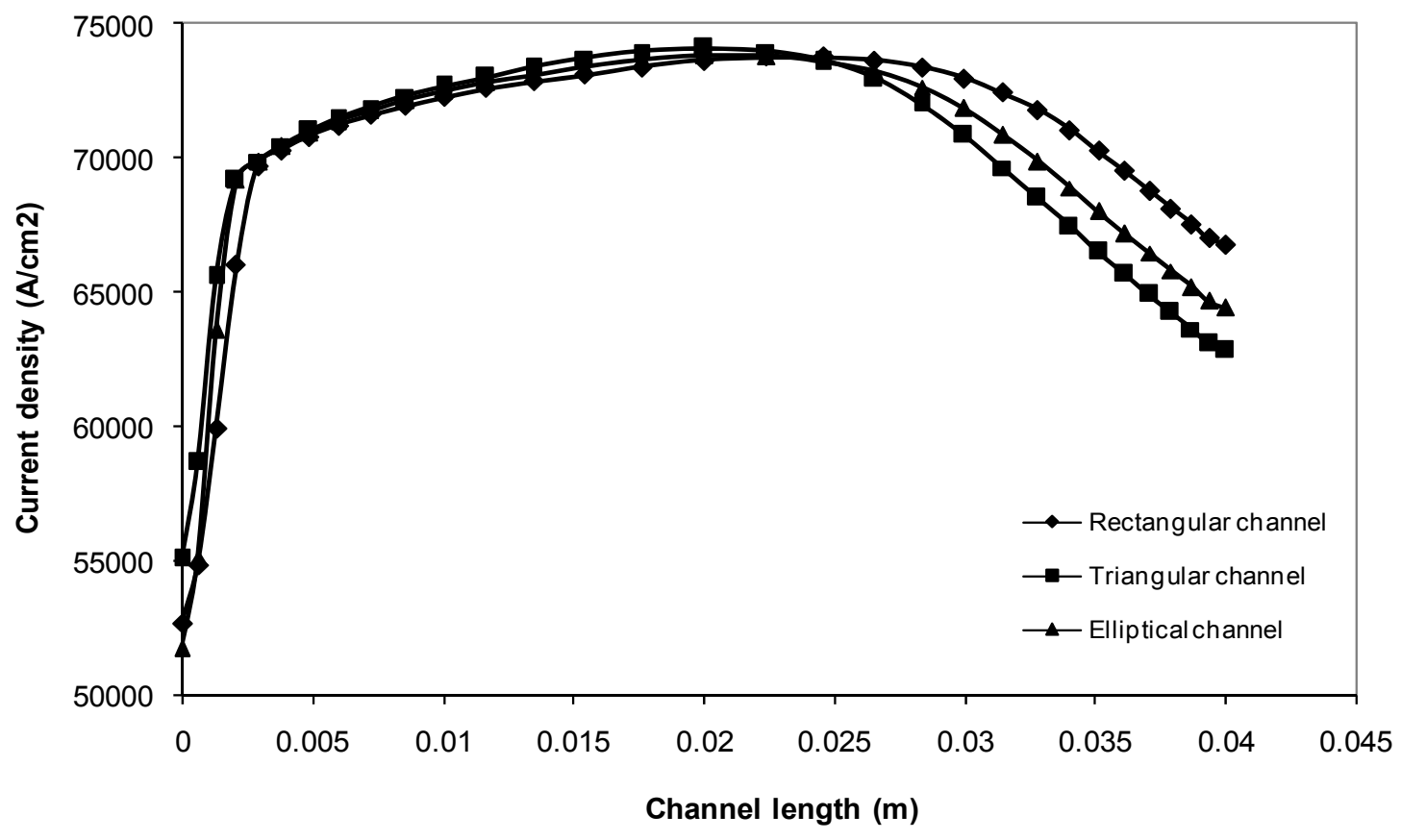

Fig.4. Local current density distributions along the catalyst surface for different channel geometries. 


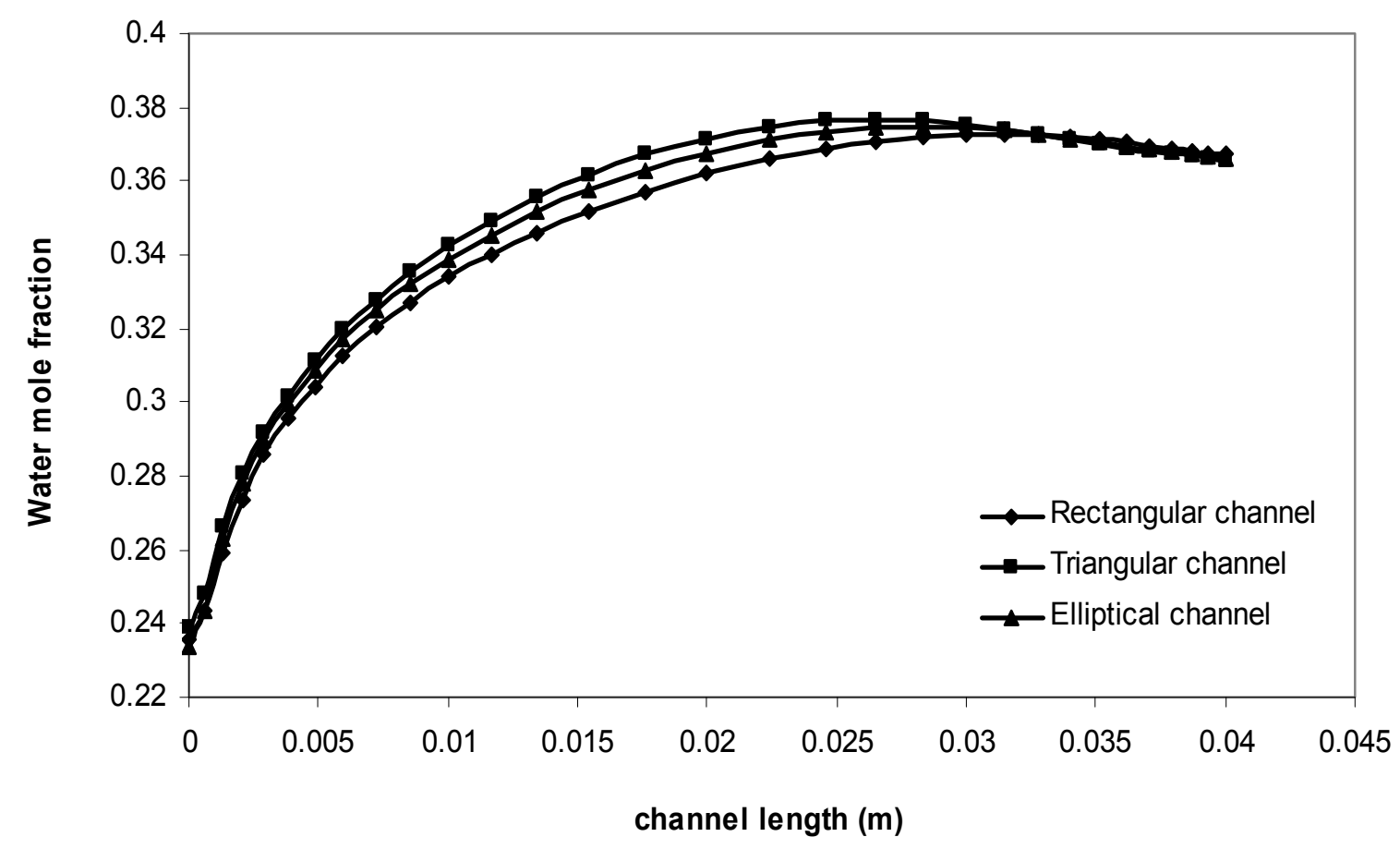

Fig.5. Local distributions of water mole fraction along the membrane for different channel geometries at $v=0.3 \mathrm{~V}$.

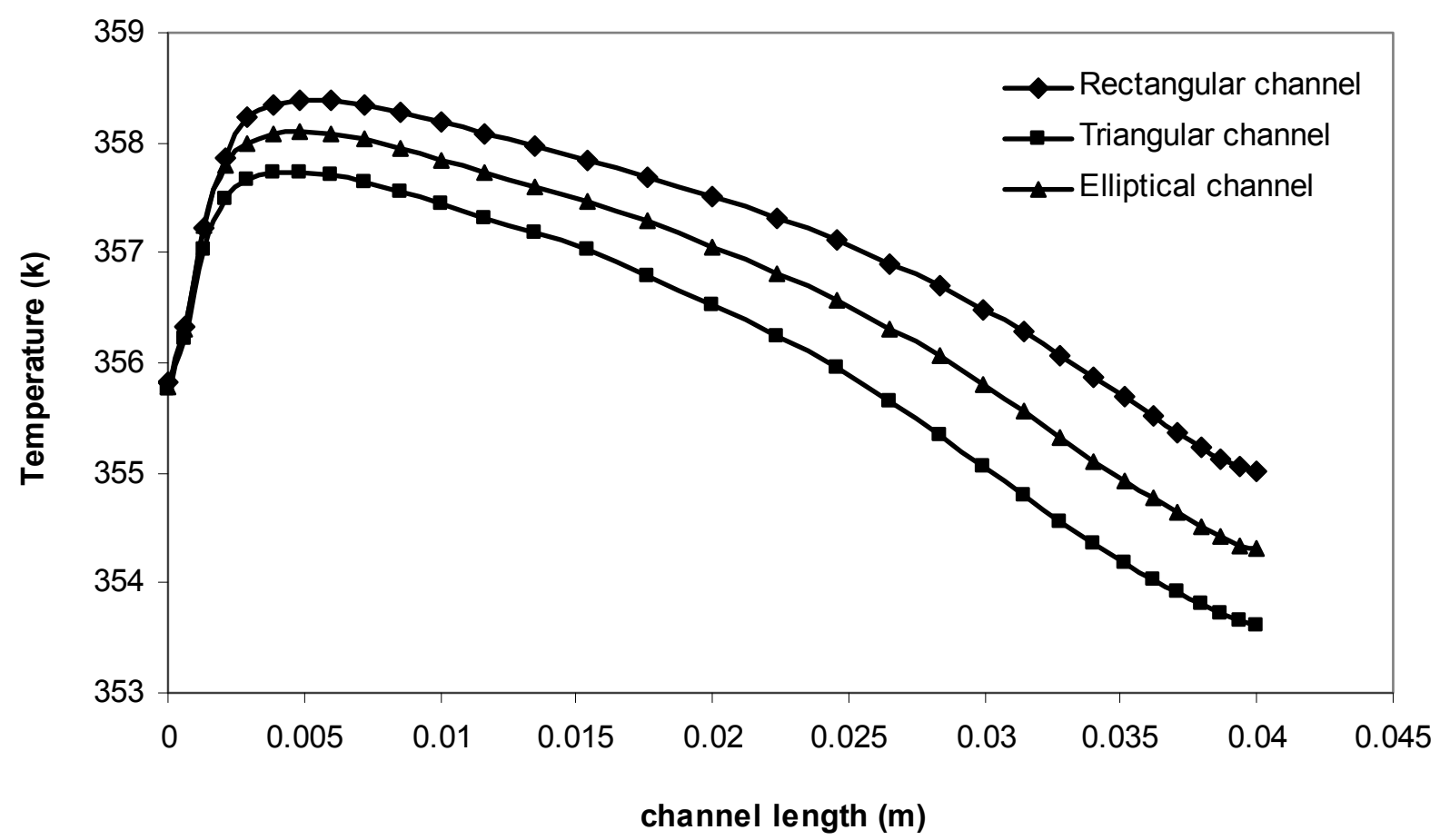

Fig.6. Local distributions of temperature along the catalyst surface for different channel geometries at $v=0.3 \mathrm{~V}$. 


\section{Conclusion}

A complete three-dimensional and single phase model for proton exchange membrane (PEM) fuel cells was used to investigate the effect of using different channel geometries on the performance, temperature and gases mole fraction. The complete three-dimensional model for PEM fuel cells based on the two-fluid method was numerically solved with constant-temperature boundary condition at surfaces of anode and cathode current collectors. The results of this paper are in good agreement with experimental results of Miansari et al. (2009). The results show that the liquid water mole fraction gradually increases with increasing $z$ direction. The results also show that a high performance was observed by using a rectangular geometry for the channels of anode and cathode sides than the triangular and elliptical geometries.

\section{Acknowgledgement}

This work was partially supported by Renewable Energy Organization of Iran.

\section{Nomenclature}

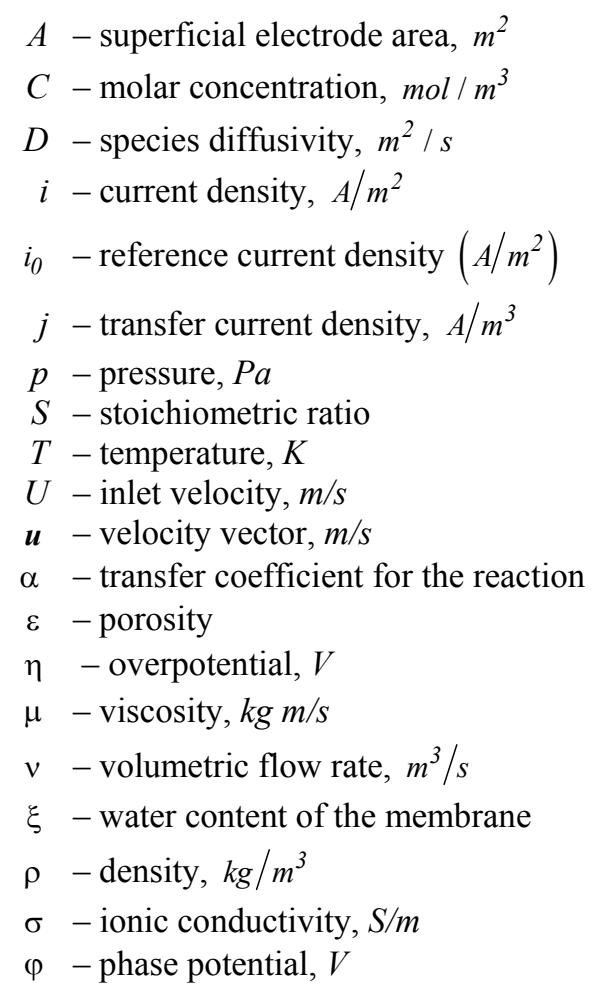

\section{References}

Chian M.S. and Chu H.S. (2006): Transient behavior of CO poisoning of the anode catalyst layer of a PEM fuel cell. J. Power Sources, vol.160, pp.340-352.

Kuo J.K., Yen T.S. and Che C.K. (2008): Improvement of performance of gas flow channel in PEM fuel cells. - Energy Conversion and Management, vol.49, pp.2776-2787.

Larminie J. and Dicks A. (2003): Fuel Cell System Explained. $-2^{\text {nd }}$ ed. Wiley. 
Miansari Me., Sedighi K., Amidpour M., Alizadeh E. and Miansari Mo. (2009): Experimental and thermodynamic approach on proton exchange membrane fuel cell performance. - J. Power Source., vol.190, pp.356-361.

Motupally S., Becker A.J. and Weidner J.W. (2000): Diffusion of water through Nafion ${ }^{\circledR} 115$ membranes. - J. Electrochem. Soc., vol.147, pp.3171-3177.

Wang Z.H., Wang C.Y. and Chen K.S. (2001): Two-phase flow and transport in the air cathode of proton exchange membrane fuel cells. - J. Power Sources, vol.94, pp.40-50.

West A.C. and Fuller T.F. (1996): The influence of rib spacing in proton-exchange membrane electrode assemblies. - J. Appl. Electrochem, vol.26, pp.557-565.

Zawodzinski T.A., Neeman M., Sillerud L.O. and Gottesfeld S. (1991): Determination of water diffusion coefficients in perfluorosulfonate ionomeric membranes. - J. Phys. Chem., vol.95, pp.6040-6044.

Zawodzinski T.A., Davey J., Valerio J. and Gottesfeld S. (1995): The water content dependence of electro-osmotic drag in proton-conducting polymer electrolytes. - Electrochimica Acta, vol.40, pp.297-302.

Received: October 1, 2011

Revised: July 27, 2012 